\title{
Equilibria Under Monetary and Fiscal Policy Interactions in a Portfolio Choice Model
}

\author{
Baruch Gliksberg* \\ The University of Haifa
}

February 22, 2016

\begin{abstract}
This paper studies how the presence of income-taxes changes the properties of general equilibrium models with monetary and fiscal policy interactions. It finds that relative to the previous literature [following Leeper (1991)] a new regime exists where a passive fiscal rule combined with a passive monetary rule can still deliver determinacy where the same area of the parameter space would lead to multiple solutions if taxes were lump sum. It characterizes analytically the extent to which tax cuts are selffinancing and how the distortionary tax Laffer curve looks near the steady state in order to obtain the size of the new regime. In the new regime, monetary and fiscal backstops are brought into play so as to rule out off equilibrium dynamics, and inflation can temporarily increase in order to increase seigniorage revenues. With this flexibility, the monetary policy is consistent with the real debt remaining bounded, and the arithmetic that follows is monetarist and unpleasant in the sense of Sargent and Wallace (1981).

JEL Codes: C62; E60; G11; H60;

Keywords: Distorting Taxes; Dynamic Laffer Curve; Monetary and Fiscal Backstops; Portfolio Choice; Unpleasant Monetarist Arithmetic;
\end{abstract}

\section{Introduction}

This paper addresses a classic question in monetary economics: what are the necessary and sufficient policy rule parameters for the existence of a unique monetary equilibrium? Unlike much of the literature, which ignores the role of fiscal rules, this paper jointly examines the role of monetary and fiscal rules in this context. Our key contribution is to consider an environment with distortionary taxes and endogenous capital accumulation. This is a nontrivial task, partly because of the difficulty of analyzing Laffer curves in a dynamic model

${ }^{*}$ Department of Economics, The University of Haifa, Mt. Carmel, Haifa 31905, Israel. Email: baruchg@econ.haifa.ac.il 
of monetary and fiscal policy interactions. Yet, relying on the apt mathematical analysis, we are able to characterize analytical boundary conditions for determinacy. The main result of this paper is that, unlike the case often explored in the literature of lump-sum taxes, in the model environment considered here there exists a "passive monetary and passive fiscal policy" regime that leads to equilibrium determinacy. In particular, this regime arises when the rate of self-financing (RSF) of tax cuts is less than unity. The intuition is that in the parameter space where tax rate increases do not raise tax revenues sufficiently, then for equilibrium determinacy, the inflation target can be increased in order to increase seigniorage revenues. In this equilibrium, determinacy is not restored through revaluation of debt, distinguishing it from the "passive monetary and active fiscal policy" regime that provides the foundation for the fiscal theory of the price level (FTPL). Because of the key role played by seigniorage revenues, we label this regime the unpleasant monetarist arithmetic regime (UMA). In addition to the above local determinacy results, we provide complementary results on global determinacy. These establish that the FTPL regime leads to a unique global equilibrium in the model.

This paper tackles issues relevant to both global and local determinacy. We perform a comprehensive analysis of the determinacy boundary characterization in an environment in which money, income taxes, government deficits, and capital accumulation are endogenous. We start with the global analysis and find that the FTPL regime ensures global determinacy in our environment. This component of the paper is a generalization of the results in Sims (1994) to a more advanced model environment. We then proceed to the local analysis, which is an advancement over Leeper (1991), and find that distortionary taxation delivers three distinct regimes. Two regimes correspond to the categorization of Leeper (1991), whereas in the third, the UMA regime, distortionary taxation limits the ability of the government to increase its revenues via tax hikes. This limitation brings about a substantial range of passive fiscal policies that interact with a passive monetary policy to deliver a unique rational expectations equilibrium. The range of passive-fiscal-passive-monetary policies is consistent with rational expectations when "fiscal limits" come into play - a situation where the rate of growth of debt/GDP is greater than the slope of the government's revenue schedule, taking into account the general equilibrium effect of tax increases on all sources of revenue. 
UMA regimes are fundamentally different from FTPL regimes. Under FTPL regimes, weak responses of government revenues to the state variables reflect a policy choice. As a result, in FTPL regimes Ricardian equivalence in equilibrium is restored via devaluation of government debt. By contrast, the intuition behind UMA regimes is similar to Sims's (1994) notion of fiscal backstop to rule out off-equilibrium dynamics. We find similarities between Sims's notion of policy backstops and UMA regimes, at least in two dimensions. First, where fiscal limits come into play, aggressive responses to inflation caused by deficits are ineffective. Since monetary contractions reduce seigniorage revenues, the inflation tax required to balance the budget increases. As a result, aggressive responses to inflation increase inflation expectations even further. Second, where the fiscal and the monetary authorities are committed to policies that satisfy the transversality condition, uniqueness can be restored by a simple policy. Given the real value of government debt, the monetary authority can announce that it will back up government debt, and the fiscal authority can announce that it will back up the value of the currency. These are credible announcements. To back its pledge the monetary authority can purchase from the private sector as much debt as needed at a promised price in exchange for currency. At the same time, the government can back up the value of the currency by exchanging money for goods, limiting the price level at some bound. This idea receives much attention in Sims (2013).

Related Literature: Leeper (1991) extends the Sargent and Wallace (1981) analysis to an environment where the monetary authority uses an interest rate instrument to respond to inflation, but does not respond specifically to debt. Subsequent to Leeper (1991), it was emphasized that with lump-sum taxes, a unique bounded solution to a rational expectations model exists under two policy regimes: Taylor rules and FTPL. Papers that discuss the role of taxation in the context of determinacy include Bhattarai, Lee, and Park (2012) and Traum and Yang (2011). Both papers characterize numerically how policy parameters affect the boundaries in large models. These works show that parameter boundaries can depend on policy targets and steady state policy values, as well as which endogenous variables the policy instruments are allowed to respond to. Carlstrom and Fuerst (2005) and Benhabib and Eusepi (2005) are influential papers that are highly relevant to the present study. Carlstrom and Fuerst (2005) study determinacy in a sticky-price money-in-utility model with capital 
accumulation and lump-sum taxes. They find that to generate determinacy, monetary policy should respond to current inflation, and that for equilibrium determinacy, continuous-time models with investment should include some cost over capital adjustment. Benhabib and Eusepi (2005) study the emergence of multiple equilibria in a cashless model with bonds (and no capital) and a cashless model with capital (and no bonds) under a wide range of monetary and fiscal policies that feature distortionary taxation and price rigidity. The authors map the determinacy bounds in the parameter space of interest responses to inflation and the Calvo parameter for price rigidity. They carefully disentangle the various effects of interest rate changes and, as a result, identify the channels that link the nominal interest rate with its effects on the marginal cost of production. In the case of capital and no bonds, the increase in the nominal rate raises the return on capital, which in turn reduces the capital stock, affecting labor productivity. In the bonds and no-capital case, the increase in the nominal rate raises the return on bonds, and thus the cost of servicing the debt. This affects the marginal product of labor via the tax increase necessitated by the tax rule.

Our study is complementary to Benhabib and Eusepi (2005). We provide a complete and analytical parameter boundary characterization for general equilibrium models that feature money, income taxes, government deficits, and capital accumulation. As Sims (2013) points out, recent expansions of central bank balance sheets and of the levels of rich-country sovereign debt, as well as the evolving political economy of the EMU, have made it clear that fiscal policy and monetary policy are intertwined. We therefore abstract from short-run, endogenous labor considerations and focus on long-run considerations that include endogenous taxes and debt stabilization. Accordingly, our analytical endeavor is to map the equilibrium bounds at the entire parameter space of interest responses and tax responses. As a result, and similar to Cochrane $(2011,2014)$, we do not restrict attention only to regimes under which the central bank responds aggressively to inflation. To simplify the analysis, we focus on flexible prices. This assumption is not uncommon, as the literature has been moving away from the assumption of price rigidity somewhat in recent years in favor of gaining analytical tractability [see for example Cochrane (2011), Sims (2013)]. Also, in combining both capital accumulation and government bonds, our model enables us to examine regimes under which monetary policy can offset adverse effects of fiscal policy. Building on the 
results of Carlstrom and Fuerst (2005), and so as to induce some cost of adjustment over capital accumulation, we impose a liquidity-in-advance constraint on investment. The main difference between Carlstrom and Fuerst (2005) and the present paper is that Carlstrom and Fuerst assume lump-sum taxes. To validate that our model behaves according to Carlstrom and Fuerst's (2005) principles, we obtain determinacy bounds for our environment when the rate of the distortionary tax falls to zero. We show, in Lemma 1, that under assumptions that mimic the case of lump-sum taxation, our results coincide with the results in Leeper (1991), thus leading to two conclusions: a) that our model is well-behaved in the sense of Carlstrom and Fuerst (2005); and b) that the change in results for our environment relative to Leeper (1991) stems from distortionary taxation. Building on the foundations laid down in Benhabib and Eusepi (2005), but from a portfolio-choice perspective, our model identifies two channels that link the nominal interest rate and the distorted, net of taxes, return on capital. Increases in the nominal rate increase the return on capital due to the liquidity-inadvance requirement over investment, which in turn reduces the capital stock, thus affecting output. Increases in the nominal rate also increase the return on bonds, and thus the cost of servicing the debt. This affects the return on capital via the tax increase necessitated by the tax rule.

The rest of the paper is organized as follows: Section 2 describes an economy with a liquidityin-advance constraint on all transactions, including investment, and a government that has access only to a distortionary taxation technology. Sections 3 discusses the determinants of equilibrium dynamics. It emphasizes the transversality condition and a concept of the Laffer curve where tax actions have general equilibrium effects over seigniorage revenues. Section 4 provides a generalization of the results in Sims (1994) on global determinacy to environments with capital accumulation and distortionary government financing. Section 5 contains the analytical derivation of local determinacy bounds in the policy parameter space. In Section 6, we present two types of quantitative exercises. The first establishes numerically the boundary conditions in the policy parameter space. The other shows impulse response functions, under the three regimes that emerge in our model, when shocks perturb the economy from the steady state. Section 7 concludes the paper. Most proofs are deferred to a technical appendix. 


\section{A Model of Portfolio Choice}

We formulate the model in continuous time to simplify the algebra and to obtain general results analytically. We consider a Ramsey-Cass-Koopmans growth model combined with a distortionary tax system and a liquidity-in-advance constraint on all transactions. In this economy, households may hold two nominal assets, money and government bonds, and a real asset, capital. To economize on notations, we abstract from stochastic transitory shocks and focus on a deterministic environment. This causes no loss of generality. The model can accommodate transitory shocks to technology, preferences, policy instruments, and money velocity by representing the relevant parameters as stochastic processes.

\subsection{The Household Sector}

The economy is closed and populated by a continuum of identical infinitely long-lived households, with measure one. The representative household enjoys consumption and is endowed with perfect foresight and one unit of time per "period". Since this paper emphasizes the importance of tax distortions and finance constraints for policy design, and given the complexity of labor market frictions, ${ }^{1}$ we abstract at this point from labor market considerations and assume that the representative household inelastically supplies its endowment of labor. Accordingly, its lifetime utility is given by

$$
U_{t}=\int_{t}^{\infty} e^{-\rho s} u\left(c_{s}\right) d s
$$

where $\rho>0$ denotes the rate of time preference, $c_{s}$ denotes consumption per capita, and $u(\cdot)$ is twice differentiable, strictly increasing, strictly concave, and satisfies the usual limit conditions. Production takes place in a competitive sector via a constant-returns-to-scale production technology $f\left(k_{t}\right)$, where $k_{t}$ denotes per-capita capital which depreciates at a rate $\delta$. Finally, $f\left(k_{t}\right)$ is concave and twice differentiable. In addition to physical capital, households may hold two nominal assets, money and government bonds. We assume that

\footnotetext{
${ }^{1}$ See an excellent review of this issue in Simer (2012). The inclusion of a realistic labor market friction in a model of monetary and fiscal policy interaction deserves attention. I leave this for another paper.
} 
money enters the economy via a liquidity constraint on all transactions and that the velocity in the circulation of money is exogenous to our model. ${ }^{2}$ Let $m_{t}$ denote the per-capita stock of money denominated in the consumption good, and let $\nu$ denote money velocity. A formal representation of the liquidity constraint is then

$$
c_{t}+I_{t} \leq \nu m_{t}
$$

where $I_{t}$ denotes per-capita investment. ${ }^{3}$ We assume that the government has access only to distortionary taxation and that deficits are financed via bond creation. As a consequence, the representative household's budget constraint becomes

$$
c_{t}+I_{t}+\dot{b_{t}}+\dot{m_{t}}=\left(R_{t}-\pi_{t}\right) b_{t}-\pi_{t} m_{t}+\left(1-\tau_{t}\right) f\left(k_{t}\right)+T_{t}
$$

where $\tau_{t} \in[0,1]$ is the income tax rate, $b_{t}$ is the real value of nominal government bonds, $R_{t}$ is the nominal rate of interest, $\pi_{t}$ is the rate of inflation, and $T_{t}$ is a real lump-sum transfer. Capital accumulates according to

$$
\dot{k_{t}}=I_{t}-\delta k_{t}
$$

Altogether, the household maximizes its lifetime utility given by (1) subject to the constraints (2)-(4), with a borrowing constraint such that $\lim _{t \rightarrow \infty} a_{t}^{H} e e_{0}^{-\int_{0}^{t}\left[R_{s}-\pi_{s}\right] d s} \geq 0$ where $a_{t}^{H} \equiv b_{t}+m_{t}$. Each household chooses sequences of $\left[\left(c_{t}, I_{t}, m_{t}\right)\right]_{t=0}^{+\infty}$ so as to maximize its lifetime utility, taking as given the initial stock of capital $k_{0}$, the initial stock of financial wealth $a_{0}^{H}$, and the time path $\left[\left(\tau_{t}, T_{t}, R_{t}, \pi_{t}\right)\right]_{t=0}^{+\infty}$, which is exogenous from the household's

\footnotetext{
${ }^{2}$ See also Alvarez et al. (2001) and Hodrick et al. (1991).

${ }^{3}$ Stockman (1981) and Abel (1985) consider a similar friction in a representative-agent framework. In our model, $\frac{1}{\nu}$ can be thought of as the inverse of money velocity. Therefore, a requirement that $\int_{t}^{t+\frac{1}{\nu}}[c(s)+I(s)] d s \leq m_{t}$ formalizes the liquidity constraint. A Taylor series expansion gives $\int_{t}^{t+\frac{1}{\nu}}[c(s)+$ $I(s)] d s=\frac{1}{\nu}[c(t)+I(t)]+\frac{1}{2}\left(\frac{1}{\nu}\right)^{2}[\dot{c}(t)+\dot{I}(t)]+\cdots ; \quad$ and $\quad \frac{1}{\nu}(c+I) \leq m \quad$ can be interpreted as a first-order approximation.
} 
viewpoint. The necessary conditions for an interior maximum are

$$
\begin{aligned}
u^{\prime}\left(c_{t}\right) & =\mu_{t} \\
\mu_{t} & =\lambda_{t}\left(1+\frac{1}{\nu} R_{t}\right) \\
\zeta_{t} & =\frac{1}{\nu} R_{t} \lambda_{t} \\
\zeta_{t}\left(\nu m_{t}-c_{t}-I_{t}\right) & =0 ; \zeta_{t} \geq 0
\end{aligned}
$$

where $\lambda_{t}, \mu_{t}$ are time-dependent co-state variables interpreted as the marginal valuations of financial wealth and capital, respectively; $\zeta_{t}$ is a time-dependent Lagrange multiplier associated with the liquidity constraint; and equation (5d) is a Kuhn-Tucker condition. The first-order conditions of the representative household are consistent with the results of Carlstrom and Fuerst (2005). Note that in general, macroeconomic continuous time modeling could be misleading in the sense that it does not correctly approximate the behavior of the discrete time model of arbitrarily small periods. Carlstrom and Fuerst (2005) point out that modeling policy issues in continuous time could lead to conclusions which are the reverse of those drawn from a discrete-time counterpart of the model. They attribute this to the difference in timing in the no-arbitrage condition of investing in bonds and capital between the two settings: while the continuous-time setting entails a contemporaneous no-arbitrage condition, a similar no-arbitrage condition in the discrete-time setting involves only future variables which bring a zero eigenvalue into the linearized dynamic system. Carlstrom and Fuerst (2005) show that one way to overcome contemporaneous features of no-arbitrage in continuous time macroeconomic models that arise as the period length gets shorter is to introduce adjustment costs to capital. Note that for equilibrium determinacy, extending the liquidity-in-advance constraint for both consumption and investment spending has the same effect as adjustment costs on capital ${ }^{4}$. Under these modelling choices, the continuous-time limit correctly approximates the behavior of a discrete-time model with arbitrarily short periods. This conclusion is consistent with the absence of an instantaneous no-arbitrage

\footnotetext{
${ }^{4}$ See Gliksberg (2009).
} 
condition between bonds and capital from the first-order conditions to the household problem in our model. Furthermore, notice that in the neighborhood of the steady state, the following conditions hold: money has a positive value, Tobin's q is strictly greater than 1, and investing agents face binding liquidity constraints. This conclusion arrives from equations (5a)-(5b): letting $q_{t} \equiv \frac{\mu_{t}}{\lambda_{t}}$ denote the marginal valuation of installed capital relative to the marginal valuation of other forms of wealth, which is the reciprocal to Tobin's q in our model economy, we obtain that $q_{t}=1+\frac{1}{\nu} R_{t}$. Since capital is not fully liquid, $q_{t}$ is greater than 1 as long as money is valued - i.e., as long as money and bonds coexist. Also note that restricting attention to positive nominal interest rates, equations $(5 \mathrm{c})-(5 \mathrm{~d})$ imply that $\zeta_{t}$ is positive, which in turn implies that the liquidity constraint is always binding. Accordingly, and after substituting $m_{t}=\frac{1}{\nu}\left(c_{t}+I_{t}\right)$ and $a_{t}^{H}=b_{t}+m_{t}$ into equation (3), the state and co-state variables must evolve according to

$$
\begin{aligned}
\frac{\dot{\lambda_{t}}}{\lambda_{t}} & =\rho+\pi_{t}-R_{t} \\
\frac{\dot{\mu_{t}}}{\mu_{t}} & =\rho+\delta-\frac{1-\tau_{t}}{1+\frac{1}{\nu} R_{t}} f^{\prime}\left(k_{t}\right) \\
\dot{k_{t}} & =I_{t}-\delta k_{t} \\
\dot{a_{t}^{H}} & =\left(R_{t}-\pi_{t}\right) a_{t}^{H}+\left(1-\tau_{t}\right) f\left(k_{t}\right)+T_{t}-\left(c_{t}+I_{t}\right)\left(1+\frac{1}{\nu} R_{t}\right) .
\end{aligned}
$$

Equations (6)-(9) summarize the effects of the interplay between monetary and fiscal policies on the representative household's decisions. The valuation of wealth, $\lambda_{t}$, is not sensitive to either the tax rate or the value of government debt. By contrast, equation (7) shows that from the perspective of the private sector, changes in the income tax rate have significant effects on the valuation of productive capital and, as a result, on the allocation of its wealth between capital and financial assets. Secondly, equations (6)-(7) describe the channel through which monetary policy can affect households' decisions. Unlike fiscal policy, monetary policy induces changes in the rate of growth of $\lambda_{t}$, as well as in the rate of growth of $\mu_{t}$. Thus, via changes in the rate of nominal interest, monetary policy can potentially mitigate adverse effects brought about by the tax distortion. Equation (9) summarizes how these actions affect the intertemporal budget constraint of the 
representative household. Solving equation (9) yields that the household's intertemporal budget constraint is of the form

$$
\begin{aligned}
& 0 \leq \lim _{t \rightarrow \infty} e^{-\int_{0}^{t}\left[R_{s}-\pi_{s}\right] d s} a_{t}^{H}= \\
& \quad a_{0}^{H}+\int_{0}^{\infty} e^{-\int_{0}^{t}\left[R_{s}-\pi_{s}\right] d s}\left[\left(1-\tau_{t}\right) f\left(k_{t}\right)+T_{t}-\left(c_{t}+I_{t}\right)\left(1+\frac{1}{\nu} R_{t}\right)\right] d t
\end{aligned}
$$

and the condition that its decisions are dynamically efficient yields the transversality condition

$$
\lim _{t \rightarrow \infty} a_{t}^{H} e^{-\int_{0}^{t}\left[R_{s}-\pi_{s}\right] d s}=0
$$

Equations (6) - (10) fully describe the optimal decision making of a representative household for which the time path $\left[\left(\tau_{t}, T_{t}, R_{t}, \pi_{t}\right)\right]_{t=0}^{+\infty}$ is exogenously given.

\subsection{The Government}

The government consists of a fiscal authority and a monetary authority. The consolidated government prints money, issues nominal bonds, collects taxes to the amount of $\tau_{t} y_{t}$ where $y_{t}$ is output, and rebates to households a lump-sum transfer $T_{t}$. Its dollar-denominated budget constraint is therefore given by $R_{t} B_{t}+P_{t} T_{t}=\dot{M}_{t}+\dot{B}_{t}+P_{t} \tau_{t} y_{t}$, where $P_{t}$ is the nominal price of a consumption bundle, $\dot{M}_{t}$ and $\dot{B}_{t}$ are net changes in the money and bond supply, respectively, and $R_{t}$ is the nominal interest paid over outstanding debt. Dividing both sides of the nominal budget constraint by $P_{t}$ and rearranging yields that government liabilities, denoted by $a_{t}^{G} \equiv \frac{M_{t}}{P_{t}}+\frac{B_{t}}{P_{t}}$, evolve according to

$$
a_{t}^{G}=\underbrace{\left(R_{t}-\pi_{t}\right) a_{t}^{G}}_{\text {interest payments on the debt }}-\underbrace{R_{t} m_{t}}_{\text {seigniorage }}+\underbrace{T_{t}-\tau_{t} y_{t}}_{\text {primary deficit }}
$$


where $\pi_{t} \equiv \frac{\dot{P_{t}}}{P_{t}}$. Equation (11) shows that since the consolidated budget is not necessarily balanced at every instant, deficits (surpluses) are financed via increments (decrements) to government debt. As a result, government liabilities increase with the primary deficit and with the real interest paid over outstanding debt, and decrease with seigniorage.

\section{Fiscal and Monetary Policies}

To enable comparison between our results and the monetary-fiscal policy interactions literature, we model open-market operations in the usual way: we assume the existence of three assets in the economy (fiat money, nominal government bonds, and capital equity); we assume that the policy instrument is the nominal rate of interest; and we assume that the central bank exchanges money and government bonds in the open market so as to induce the desired nominal rate of interest. We follow Leeper's (1991) path and consider simple policy rules that allow scrutiny of first-order consequences of the time paths of nominal interest and income-tax rates. We assume that monetary policy follows a simple version of an interest rate feedback rule,

$$
R\left(\pi_{t}\right)=\rho+\pi^{*}+\alpha\left(\pi_{t}-\pi^{*}\right), \quad \text { where } \quad \alpha>0 .
$$

In Leeper's (1991) terminology, a monetary rule that exhibits $\alpha>1$ is called an active monetary policy, while $\alpha<1$ corresponds to a passive monetary policy. We also assume an exogenous path for lump-sum transfers,

$$
T_{t}=T^{*}
$$

Finally, we assume that fiscal policy follows rules which embed two features. First, there may be some automatic stabilizer component to movements in fiscal variables. This is modeled as a contemporaneous response to deviations of output from the steady state. Second, the income-tax rate is permitted to respond to the state of government debt. Altogether, the 
fiscal authority sets the income-tax rate according to

$$
\tau\left(y_{t}, a_{t}^{G}\right)=\tau^{*}+\beta \frac{y_{t}-y^{*}}{y^{*}}+\gamma \frac{a_{t}^{G}-a^{*}}{a^{*}}, \quad \text { where } \quad \beta, \gamma \geq 0
$$

and $y^{*}, a^{*}$ are long-run output and a debt target, respectively. This rule is consistent with much of the empirical literature. Prominent papers which emphasize that tax rates may adjust to stabilize government debt include Bi (2012), Bi and Traum (2012), Bi, Leeper and Leith (2013), Leeper and Yang (2008), and Leeper, Plante, and Traum (2010).

\subsection{General Equilibrium}

In equilibrium, a) the goods market clears

$$
f\left(k_{t}\right)=y_{t}=c_{t}+I_{t},
$$

b) the money market clears

$$
\frac{M_{t}}{P_{t}}=m_{t}=\frac{1}{\nu}\left(c_{t}+I_{t}\right)
$$

and c) the assets market clears

$$
\frac{M_{t}+B_{t}}{P_{t}}=a_{t}=a_{t}^{H}
$$

Imposing market clearing conditions (15)-(17), and assuming that the elasticity of intertemporal substitution in consumption is constant, we arrive at the following characterization of the general equilibrium of the economy:

Proposition 1 In equilibrium with distortionary financing, the aggregate dynamics satisfy 
the policy rules (12)-(14) combined with the following ODE system:

$$
\begin{aligned}
& \dot{\dot{c}_{t}}=\sigma\left\{\frac{1-\tau\left(f\left(k_{t}\right), a_{t}\right)}{1+\frac{1}{\nu} R\left(\pi_{t}\right)} f^{\prime}\left(k_{t}\right)-(\rho+\delta)\right\} \\
& \dot{\dot{\pi}_{t}}=\frac{\nu+R\left(\pi_{t}\right)}{\alpha}\left\{\left[R\left(\pi_{t}\right)-\pi_{t}\right]-\left[\frac{1-\tau\left(f\left(k_{t}\right), a_{t}\right)}{1+\frac{1}{\nu} R\left(\pi_{t}\right)} f^{\prime}\left(k_{t}\right)-\delta\right]\right\} \\
& \dot{k_{t}}=f\left(k_{t}\right)-c_{t}-\delta k_{t} \\
& \dot{a_{t}}=\left[R\left(\pi_{t}\right)-\pi_{t}\right] a_{t}+T_{t}-\left[\tau\left(f\left(k_{t}\right), a_{t}\right)+\frac{1}{\nu} R\left(\pi_{t}\right)\right] f\left(k_{t}\right) .
\end{aligned}
$$

Equation (18) is an Euler equation, where $\sigma>0$ denotes the elasticity of intertemporal substitution in private consumption. In our economy the marginal product of capital is distorted by the income tax and liquidity constraints. Notice that with no distortions, equation (18) becomes the familiar Ramsey-type Euler equation. Equation (19) was obtained by taking a time derivative from the first-order condition $(5 a)$ and substituting in equation (6). It corresponds to a Fisher equation in which the nominal rate of interest varies with expected inflation and the real rate of interest. This equation shows that since capital and bonds are perfect substitutes at the private level, in equilibrium the distorted marginal product of capital net of depreciation must equal the real interest received from holding a risk-free bond minus the expected change in inflation after the policy response to inflation is internalized. Finally, equations (20)-(21) were obtained by substituting market clearing conditions (15)-(17) into equations (8)-(9). At this point we can characterize the equilibrium as follows:

Definition 1 An equilibrium with distortionary financing is a set of sequences $\left\{\left[\left(c_{t}, \pi_{t}, k_{t}, a_{t}, \tau_{t}, T_{t}, R_{t}\right)\right]_{t=0}^{+\infty}\right.$ satisfying (18)-(21) and (12)-(14), given $k_{0}>0$ and $B_{0}+M_{0}>0$. 


\subsection{Steady State Equilibrium}

It follows from equation (18) that in a steady state,

$$
f^{\prime}\left(k^{*}\right)=(\rho+\delta) \frac{1+\frac{1}{\nu} R^{*}}{1-\tau^{*}}
$$

where $\tau^{*}$ denotes a long-run income tax rate and $R^{*}$ is a steady-state rate of interest. We can see the distorting effect of income taxes and interest rates on output as the marginal product of capital increases with both distortions. From equations (19) and (22), $R^{*}$ must satisfy

$$
R^{*}=\rho+\pi^{*}
$$

where $\pi^{*}$ is the long-run rate of inflation. Equation (20) implies that the steady-state consumption is

$$
c^{*}=f\left(k^{*}\right)-\delta k^{*} .
$$

Finally, equation (21) shows that in a steady-state equilibrium, government liabilities must

satisfy $a^{*}=\frac{1}{\rho}\left[f\left(k^{*}\right)\left(\tau^{*}+\frac{1}{\nu} R^{*}\right)-T^{*}\right]$. Let $\widetilde{a}^{*} \equiv \frac{a^{*}}{f\left(k^{*}\right)}, \widetilde{T}^{*} \equiv \frac{T^{*}}{f\left(k^{*}\right)}$, denoting debt/GDP and transfers/GDP in the steady state, respectively. So, a sustainable debt must satisfy

$$
\widetilde{a}^{*}=\frac{1}{\rho}\left[\tau^{*}+\frac{1}{\nu} R^{*}-\widetilde{T}^{*}\right]
$$

\section{Determinants of Equilibrium Dynamics}

\subsection{The Fiscal Stance and the Transversality Condition}

The system (18)-(21) shows that in equilibrium, markets clear and households rationally internalize the policy rules. Also, to characterize equilibrium correctly we must impose the condition that the household's intertemporal budget constraint holds with equality. Note, 
however, that the choice of $\gamma$ determines the rate of growth of government debt. In order to study the effect of $\gamma$ on the evolution of government debt, we substitute the fiscal rule (14) into (21) and obtain that government debt evolves according to

$$
\dot{a}_{t}=\left[R\left(\pi_{t}\right)-\pi_{t}-\gamma \frac{f\left(k_{t}\right)}{a^{*}}\right] a_{t}-f\left(k_{t}\right)\left[\tau^{*}+\beta \frac{f\left(k_{t}\right)-f\left(k^{*}\right)}{f\left(k^{*}\right)}-\gamma+\frac{1}{\nu} R\left(\pi_{t}\right)\right]+T^{*} .
$$

Solving equation (26) for $a_{t}$ and letting $t \rightarrow \infty$, we arrive at

$$
\lim _{t \rightarrow \infty} Q_{t} a_{t}=a_{0}-\int_{0}^{\infty} Q_{s} X_{s} d s
$$

where $Q_{t} \equiv e^{-\int_{0}^{t}\left[\left(R\left(\pi_{s}\right)-\pi_{s}\right)-\gamma \frac{f\left(k_{s}\right)}{a^{*}}\right] d s}, X_{s} \equiv\left\{\left[\tau^{*}+\beta \frac{f\left(k_{s}\right)-f\left(k^{*}\right)}{f\left(k^{*}\right)}-\gamma+\frac{1}{\nu} R\left(\pi_{s}\right)\right] f\left(k_{s}\right)-T^{*}\right\}$.

$X_{s}$ is the surplus at instant $s$ and $Q_{s}$ is its respective discount factor. As we assume that transfers are constant, the surplus flow has two components. The first consists of revenues from taxing all sources of income in the economy. Note that the tax rate includes an automatic stabilizer component, which we modeled as a response of the income tax rate to deviations of output from the steady state. The second component comprises seigniorage revenues. Also note that the discount factor has two components. The first stems from monetary policy and equals the real rate of interest, while the second stems from fiscal policy and attaches a growth premium to the surplus flow. Rearranging eq. (27) produces

$$
\lim _{t \rightarrow \infty} e^{-\int_{0}^{t}\left[R\left(\pi_{s}\right)-\pi_{s}\right] d s} a_{t}=\lim _{t \rightarrow \infty}\left[\frac{a_{0}-\int_{0}^{t} Q_{s} X_{s} d s}{e^{0} \gamma \frac{f\left(k_{s}\right)}{a^{*}} d s}\right]
$$

As we know, the left-hand side of the equation must equal zero in equilibrium. If $\gamma$ is large enough, real debt will shrink back to its long-run level and the transversality condition is ensured. By contrast, if $\gamma$ is too small, it may appear that the government is letting its debt grow too fast. In what follows we reestablish some previous results in the context of our 
model, and highlight new results that emerge from our model. We start by defining passive and active fiscal policies.

Definition 2 Fiscal policy is considered passive if the exogenous sequences and feedback rules that specify the policy regime imply that the transversality condition necessarily holds for any initial level of government debt. Otherwise fiscal policy is considered active.

In view of definition 2 , equation (28) has the following implications:

Proposition 2 Fiscal rules are passive if and only if $\gamma \geq \rho \widetilde{a}^{*}$.

Where $\gamma \geq \rho \widetilde{a}^{*}$, both the numerator and the denominator of the right-hand side of eq. (28) expand to infinity, and it is important to determine which grows faster. It is straightforward to show via L'Hospital's law that where $\gamma \geq \rho \widetilde{a}^{*}$, the limit of the expression on the right-hand side of eq. (28) is zero. Thus, policy rules that exhibit $\gamma \geq \rho \widetilde{a}^{*}$ ensure that the household's transversality condition is not violated. Policy stances of this type imply that the government ensures that its liabilities will converge back to the target. In particular, in this regime the government is committed to ensuring fiscal solvency for any given initial real value of government debt.

Proposition 3 Fiscal rules are active if and only if $\gamma<\rho \widetilde{a}^{*}$. In this case the initial real value of government debt, $a_{0}$, is the solution to a fixed-point problem $a_{0}=\int_{0}^{\infty} Q_{s} X_{s} d s$ where the sequence $\left[\left(Q_{s} X_{s}\right)\right]_{t=0}^{+\infty}$ is obtained taking $a_{0}$ as given.

Notice the transversality condition (28). For any $\gamma \in\left(0, \rho \widetilde{a}^{*}\right), Q_{t}$ is contracting. Note, however, that the transversality condition may hold even in cases where the numerator at the right-hand side of eq. (28) is not zero, i.e. in cases where the government may violate its budget constraint. This result has an important implication as global determinacy becomes a central issue where fiscal policy is active. Where taxes are lump-sum, future surpluses are independent of real allocation. In this case, if fiscal policy is active, it is possible to pinpoint the initial value of government debt based on the surpluses alone. In contrast, where the 
government has access only to distortionary taxation, tax revenues become a feature of equilibrium. In that case, if fiscal policy is active, the initial value of government debt is equal to the present value of future surpluses. However, future surpluses are generated by endogenous variables that in turn depend on the initial conditions of the economy - the initial stock of productive capital and the initial real value of government liabilities. Thus, an active stance of the fiscal authority that has access only to distortionary taxation brings about a situation where the initial value of its liabilities and the entire equilibrium trajectory must be determined simultaneously. We pay much attention to this issue in section 4 , where we discuss global determinacy.

\subsection{The Laffer Curve and the Stable Manifold}

In what follows we propose terminology required to discuss dynamic Laffer curves in the context of monetary and fiscal policy interactions. Let $\dot{x}_{t}=g\left(x_{t}\right)$ denote the system of equations (18)-(21). Then a linear approximation near the steady state reads

$$
\dot{x_{t}}=B \times\left(x_{t}-x^{*}\right)
$$

and we obtain analytically that the product of the system's eigenvalues is ${ }^{5}$

$-\left[\widetilde{c}^{*} \nu \sigma \rho f_{k}^{* 2}\right] \frac{\alpha-1}{\alpha}\left[\beta+\frac{\tau^{*}}{1-\varphi^{*}}+\frac{\gamma}{\rho \tilde{a}^{*}}\left(\frac{1}{\nu} R^{*}-\frac{\tau^{*} \varphi^{*}}{1-\varphi^{*}}\right)\right]$

where $\varphi_{\left(\tau_{t}, y_{t}\right)} \equiv \frac{\partial \ln \left(\tau_{t} y_{t}\right)}{\partial \ln \left(\tau_{t}\right)}=1+\frac{\partial \ln \left(y_{t}\right)}{\partial \ln \left(\tau_{t}\right)}$ denotes the marginal revenue generated from an increase in taxes, and $\varphi_{\left(\tau_{t}, y_{t}\right)}$ can be interpreted as the slope of the income-tax Laffer curve. The second term is negative as higher taxes reduce output, so the elasticity of tax revenue with respect to tax rates is less than one. In this economy $y_{t}=f\left(k_{t}\right)$. Accordingly, $\varphi_{\left(\tau_{t}, y_{t}\right)}=1+\frac{\tau_{t}}{f\left(k_{t}\right)} \frac{\partial f\left(k_{t}\right)}{\partial \tau_{t}}=1+\frac{\tau_{t}}{f\left(k_{t}\right)} f^{\prime}\left(k_{t}\right) \frac{d k_{t}}{d \tau_{t}}$.

It is straightforward to obtain ${ }^{6}$ that $\frac{d k^{*}}{d \tau^{*}}=\frac{1}{1-\tau^{*}} \frac{f^{\prime}\left(k^{*}\right)}{f^{\prime \prime}\left(k^{*}\right)}$, and therefore the slope of the incometax Laffer curve near the steady state reads

$$
\varphi_{\left(\tau^{*}\right)}=1+\frac{\tau^{*}}{1-\tau^{*}} \frac{\left[f^{\prime}\left(k^{*}\right)\right]^{2}}{f\left(k^{*}\right) f^{\prime \prime}\left(k^{*}\right)} .
$$

\footnotetext{
${ }^{5}$ See the technical appendix.

${ }^{6} \mathrm{By}$ applying the implicit function theorem on equation (22).
} 
The slope is related to the degree to which a tax cut is self-financing, defined as the ratio of additional tax revenues due to general equilibrium effects and the lost tax revenues due to the tax cut. More formally, adopting the terminology of Trabandt and Uhlig (2011) with adjustments to a monetary economy, the degree to which a tax cut is self-financing, denoted by $\mathcal{R S F}$, is calculated as

$\mathcal{R S F}=1-\frac{1}{f\left(k^{*}\right)} \frac{d\left[f\left(k^{*}\right)\left(\tau^{*}+\frac{1}{\nu} R^{*}\right)\right]}{d \tau^{*}}$

where $f\left(k^{*}\right)\left(\tau^{*}+\frac{1}{\nu} R^{*}\right)$ are total revenues in the steady state. With no endogenous changes in allocations following a tax change, the loss in tax revenue due to a one-percentage-point reduction in the tax rate would be one percent of $f\left(k^{*}\right)$, and the self-financing rate would calculate to zero. By contrast, in a non-monetary economy, at the peak of the income-tax Laffer curve, tax revenue would not change at all in the wake of a one-percentage-point reduction in the tax rate, and the self-financing rate would be one. Note that in our economy, households hold money, so seigniorage is a source of revenue. Thus, tax cuts may affect seigniorage revenues via general equilibrium effects. All in all, we find that the rate of self-financing in a monetary economy near the steady state depends on the elasticity of tax revenues, the tax-rate target, and the inflation target, and reads

$$
\mathcal{R S F}^{*}=1-\frac{\varphi^{*}-1}{\tau^{*}}\left[\frac{1}{\nu} R^{*}-\frac{\tau^{*} \varphi^{*}}{1-\varphi^{*}}\right]
$$

In contrast, in a non-monetary economy the rate of self-financing should equal one minus the elasticity of tax revenues. Also note that in our model economy, the rate of self-financing near the steady state increases with the nominal interest rate. We can thus conclude that, ceteris paribus, introducing money into an otherwise non-monetary model with distorting taxation causes rates of self-financing of tax cuts to increase.

At this point it is helpful to introduce a notation that is used in the rest of the paper:

$\phi_{\alpha} \equiv \frac{\alpha-1}{\alpha}$

$\phi_{\beta} \equiv \beta+\frac{\tau^{*}}{1-\varphi^{*}}$

$\phi_{\gamma} \equiv \frac{\gamma}{\rho \tilde{a}^{*}}$

where $\phi_{\alpha}$ describes interest responses to deviations of inflation from its target, $\phi_{\beta}$ describes 
a tax response to deviations of output from its target, and $\phi_{\gamma}$ describes a tax response to excess debt accrued by past deficits. One can think of $\phi_{\alpha}$ as the net effect of the monetary response on the real rate of interest when inflation is above target. Thus, a negative $\phi_{\alpha}$ implies that the monetary policy lets the real rate of interest drop below its long-run level when inflation is above its target. $\phi_{\alpha}>0$ corresponds to active rules that strongly react to inflation, and monetary rules that exhibit $\phi_{\alpha}<0$ are considered passive. Similarly, one can think of $\phi_{\gamma}$ as the effect of secondary deficits on tax hikes. According to this interpretation, $\phi_{\gamma}=1$ should imply that only the interest paid on the government debt is financed via tax hikes, and $\phi_{\gamma}>1$ should imply that when debt increases above its long-run level, income taxes rise more than needed to fully offset all the excess interest payments. According to Proposition 2, such fiscal rules are passive. Equivalently, $\phi_{\gamma}<1$ implies that when debt rises above its long-run level, income taxes may also rise. However, in this case tax revenues are insufficient to stop the debt from growing. According to Proposition 3, such rules are active. Let $r_{i} \quad i=1, . ., 4$ denote the eigenvalues of $B$. Then, having the expressions for the trace and determinant of $\mathrm{B}$, we obtain that

$$
\begin{aligned}
r_{1} r_{2} r_{3} r_{4} & =-\kappa \phi_{\alpha}\left[\phi_{\beta}+\phi_{\gamma}\left(\mathcal{R S F}^{*}-1\right) \frac{\tau^{*}}{1-\varphi^{*}}\right] \\
r_{1}+r_{2}+r_{3}+r_{4} & =2 \rho+\left(\nu+R^{*}\right) \phi_{\alpha}+f_{k}^{*}-\rho \phi_{\gamma}
\end{aligned}
$$

where $\kappa \equiv \widetilde{c}^{*} \nu \sigma \rho f_{k}^{* 2}>0$ is a constant.

When $\mathrm{B}$ has no eigenvalues with zero real parts, the steady state $x^{*}$ is a hyperbolic fixed point for which the Hartman-Grobman Theorem and the Stable Manifold Theorem for nonlinear systems hold. As a result, the asymptotic behavior of solutions near $x^{*}-$ and hence its stability type - are determined by the linearization (29). Thus, we can discuss the determination of real variables near the steady-state equilibrium:

Definition 3 The equilibrium displays real determinacy if there exists a unique solution to 


$$
\dot{x_{t}}=B \times\left(x_{t}-x^{*}\right) .
$$

Given that $\left(k_{t}, a_{t}\right)$ are predetermined, Proposition 4 follows directly from equation (32):

Proposition 4 The steady state $x^{*}$ is hyperbolic if and only if $\phi_{\alpha}\left[\phi_{\beta}+\phi_{\gamma}\left(\mathcal{R} \mathcal{S} \mathcal{F}^{*}-1\right) \frac{\tau^{*}}{1-\varphi^{*}}\right] \neq$ 0. Necessary conditions for real determinacy are that

$$
\begin{array}{r}
\phi_{\alpha}\left[\phi_{\beta}+\phi_{\gamma}\left(\mathcal{R} \mathcal{S} \mathcal{F}^{*}-1\right) \frac{\tau^{*}}{1-\varphi^{*}}\right] \\
\phi_{\beta}>0
\end{array}
$$

Furthermore, as long as the fiscal rule is "sound" in the sense that it exhibits $\phi_{\beta}>0$, the response of the income tax rate to output has no effect on determinacy boundaries.

Proposition 4 states that fiscal policies which exhibit $\left[\phi_{\beta}+\phi_{\gamma}\left(\mathcal{R S F}^{*}-1\right) \frac{\tau^{*}}{1-\varphi^{*}}\right]>0$ must interact with a passive monetary policy. Note that $\frac{d \ln \left[\frac{1-\tau\left(k_{t}, a_{t}\right)}{1+\frac{1}{\nu} R\left(\pi_{t}\right)} f^{\prime}\left(k_{t}\right)\right]}{d \ln f\left(k_{t}\right)} \approx-\frac{1}{1-\tau^{*}} \phi_{\beta}$. That is, the evolution of after-tax marginal product of capital along an equilibrium trajectory is sensitive to countercyclical tax actions. If, for example, fiscal policy exhibits responses to output such that $\phi_{\beta}<0$, the after-tax marginal product of capital becomes positively associated with output, and such policies induce multiple equilibria. The intuition is as follows: start from a steady state equilibrium, and suppose that the future return on capital is expected to increase. Indeterminacy cannot occur without distorting taxes, since a higher capital stock is associated with a lower rate of return under constant returns to scale. However, a feedback income-tax rule that exhibits $\phi_{\beta}<0$ causes the after-tax return on capital to rise even further, thus validating agents' expectations, and any such trajectory is consistent with equilibrium. By contrast, a stance such that $\phi_{\beta}>0$ reduces higher anticipated returns on capital from belief-driven expansions, thus preventing expectations from becoming self-fulfilling. Hence, from now on we assume that $\phi_{\beta}>0$. 


\section{Debt Revaluation under Active Fiscal Policies}

In what follows we discuss regimes that feature responses of the tax rate to public debt at magnitudes $\gamma<\rho \widetilde{a}^{*}$. We show that such regimes are generalizations of Sims' (1994) fiscal theory of the price level. We henceforth label this set of regimes as FTPL regimes. In the literature, FTPL regimes are distinguished from other regimes on two main fronts. First, an FTPL regime requires nominal debt, as the key mechanism requires a revaluation of debt. Second, an essential element of studies that analyze equilibria where the FTPL may hold is that they have to tackle global determinacy. In what follows we outline a theory aimed at convincing the reader that a) the FTPL regime that emerges in our model is distinctive, and b) the FTPL regime ensures global determinacy.

Our theory has three central poles. The first involves the transformation of an unstable boundary value problem into a stable initial value problem. ${ }^{7}$ The second is the idea that an approximation of the infinite time horizon is endogenously determined. This depends on the initial deviation of the backward-looking system from its steady state. ${ }^{8}$ The third is that our approach must deliver a unique valuation to government debt. We know by now that distortionary taxation combined with an active fiscal policy implies that the real value of government debt and the equilibrium trajectory must be determined simultaneously. We build on the Krasnoselski-Mann-Bailey theorem ${ }^{9}$ to prove that in our model economy, any FTPL regime delivers a unique determination of the initial real value of financial wealth and, as a result, a unique determination of the entire equilibrium trajectory. With reference to our model economy, Mann's and Bailey's theorems imply that if a continuous non-expanding function takes a closed interval of the real line, $\left[a_{1}, a_{2}\right]$, into itself and has a unique fixed point, $z$, in $\left[a_{1}, a_{2}\right]$, then a Bailey's sequence of that function converges to $z$ for all choices of initial guesses in $\left[a_{1}, a_{2}\right]$. This brings us to the point where we can calculate equilibrium valuations of government debt under FTPL regimes. We recognize that given the initial

\footnotetext{
${ }^{7}$ See for example Mulligan and Sala-i-Martin (1991, 1993).

${ }^{8}$ See for example Buiter (1984) and Sims (2002). This approach is very different from a backward-shooting approach because shooting always implies the possibility of missing the target, while backward integration obtains the solution from a given initial value to a given steady state up to a predetermined error at the first shot.

${ }^{9}$ See reference in the technical appendix.
} 
stock of capital, the monetary rule, and the fiscal rule, the present value of future surpluses becomes a function of the valuation of government debt. The latter measure thus becomes a mapping from a closed interval on the real line to itself. As a result, it is straightforward to obtain the initial value of government debt as a limit to a Krasnoselski-Mann-Bailey sequence. The formal argumentation is the following:

Corresponding to the autonomous system $\dot{x}_{t}=g\left(x_{t}\right)$, specified in Proposition 1 and where $g: W \rightarrow E$, there are maps $\Phi: \Omega \rightarrow W$ where $(t, c, \pi, k, a, \tau, T, R, P) \in \Omega$ satisfying $\Phi_{t}=g\left(\Phi_{t}\right)$ and the necessary conditions specified in Proposition 4. In view of definition 1, $\Phi_{t}$ is defined by letting $\Phi_{t}(c, \pi, k, a, \tau, T, R, P) \equiv \Phi(t, c, \pi, k, a, \tau, T, R, P)$ be a solution curve sending 0 to $\left(c_{0}, \pi_{0}, k_{0}, a_{0}, \tau_{0}, T_{0}, R_{0}, P_{0}\right)$ and sending $+\infty$ to $\left(c^{*}, \pi^{*}, k^{*}, a^{*}, \tau^{*}, T^{*}, R^{*}, P^{*}\right)$. Consider a hyperbolic stationary solution to the system $\dot{\Phi}_{t}=g\left(\Phi_{t}\right)$ and a trajectory that lies on a stable manifold. In the context of our model, and given that we have two predetermined variables, the trajectory is isolated if and only if the dimension of the stable manifold is two [see Tables A.1 in the technical appendix]. We focus on the characteristics of policy interactions that bring about isolated solutions in the next section. At the moment we assume that $\Phi_{t}$ is isolated and focus on the conditions for global determinacy. Note that at the outset $\Phi_{t}$ may exhibit global indeterminacy, because from a global perspective, a solution that lies on the stable manifold should meet at least two requirements in order to be consistent with equilibrium. First, $\Phi_{t}$ should converge to $\Phi^{*}$, whereas the system of equations (18) - (21) determines only four dimensions of the steady state. Therefore, the system (18) - (21) alone renders the steady state itself indeterminate. Hence we need at the outset to specify how to select a unique eight-dimensional steady state from the set of stationary solutions to $\dot{\Phi}_{t}=g\left(\Phi_{t}\right)$. Second, note that the time path of nominal prices is determined only if the time path of inflation, $\left[\left(\pi_{t}\right)\right]_{t=0}^{+\infty}$, is unique and $P_{0}$ is determined. Thus, we should at the outset specify how to pinpoint the initial price level $P_{0}$. This brings us to the following definition:

Definition 4 (Global Determinacy) The equilibrium with distortionary financing displays global determinacy if $\Phi_{t}=g\left(\Phi_{t}\right)$ has:

a) a unique stationary solution $\Phi^{*}$, and b) a unique initial price level $P_{0}$, and 


\section{c) a unique $\Phi_{t}$ that converges to $\Phi^{*}$.}

This leads us to the following proposition:

Proposition 5 A necessary condition for global determinacy is that the government proclaims three targets and credibly implements a fiscal rule $T_{t}=T^{*}$ that is implied by the explicit targets.

Note that the steady state is sustained only if the revenues from taxes and seigniorage equal the sum of transfers and debt service. Thus, as equation (25) links $\pi^{*}, \tau^{*}, a^{*}, T^{*}$ to a balanced-budget condition, three targets should be specified "exogenously", and the fourth is implied by the stipulation to run a balanced budget in the steady state. We can thus conclude that a government that is committed to achieving $\left(\pi^{*}, \tau^{*}, a^{*}\right)$ via the rules (12)-(14) implicitly stipulates for promised transfers according to $T_{t}=T^{*}=\left[\tau^{*}+\frac{1}{\nu} R^{*}\right] f\left(k^{*}\right)-\rho a^{*}$ for all $t$. In the rest of the paper we assume that the government chooses $\left(\pi^{*}, \tau^{*}, a^{*}\right)$ as "exogenous targets" and redistributes to the households the amount $T^{*}$ that is implied by eq. (25).

Note that proclaiming three targets is necessary for global determinacy, but not sufficient. In order to induce global determinacy the government should also take actions that ensure a unique determination of $P_{0}$ even where the initial conditions are far from the steady state. We will now prove that under FTPL, any homeomorphism $\Phi_{t}$ that lies on the stable manifold is globally determinate. Let $\Psi \equiv \int_{0}^{\infty} Q_{s} X_{s} d s$ indicate the present value of future primary surpluses. Then $\Psi: W^{\prime} \rightarrow \Re_{+}$corresponds to the mapping of the flow $\Phi_{t}$ into a positive real number where the domain $W^{\prime} \subset W$ is a subset generated by active fiscal rules. Let $\digamma$ denote the composition $\Psi \circ \Phi$. Then $\digamma: \Omega \rightarrow \Re_{+}$, and $\widetilde{\digamma}\left(a_{t}\right) \equiv \digamma\left(a_{t} \mid \Phi_{t}, \Phi^{*}\right)$ returns the present value of future primary surpluses as a function of the valuation of government liabilities, given the state of the economy. ${ }^{10}$ We emphasize that $\widetilde{\digamma}\left(a_{t}\right)$ is well-defined only where $Q_{s}$ is contracting. Since $Q_{s}$ is contracting only under FTPL regimes [see Propositions 2-3], an important corollary of this statement is that $\widetilde{\digamma}\left(a_{t}\right)$ is well-defined only under FTPL. In

\footnotetext{
${ }^{10}$ The state of the economy is represented by a vector that contains the predetermined variables, the policy instruments and the distance of the state variables from their steady-state levels.
} 
particular, $\widetilde{\digamma}: \Re_{+} \rightarrow \Re_{+}$is a single-dimensional function that measures the effect of the state variable $a_{t}$ on the valuation of government debt, taking as given all other variables. According to this terminology, the economy is in equilibrium if and only if $\forall t \in[0,+\infty) \quad a_{t}=\widetilde{F}\left(a_{t}\right)$. For example, we can say we have pinned down the initial value of financial wealth if we obtain an $a_{0}$ that is a solution to $a_{0}=\widetilde{\digamma}\left(a_{0}\right)$. Similarly, the economy is in its steady state when $a^{*}=\widetilde{\digamma}\left(a^{*}\right)=\frac{1}{\rho}\left[f\left(k^{*}\right)\left(\tau^{*}+\frac{1}{\nu} R^{*}\right)-T^{*}\right]$.

A crucial feature of $\widetilde{\digamma}$ stems from the active stance of the fiscal authority under an FTPL regime. In such regimes, increments to the real value of government debt are met by tax actions that do not fully offset the increase in government debt, and therefore cause a less than one-for-one increase in the present value of future surpluses. The formal representation of this stance is $\frac{\partial \widetilde{\digamma}}{\partial a}<1$, which leads us to the following result:

Proposition 6 Under FTPL regimes $\widetilde{\digamma}(a)$ is a non-expanding mapping.

Proof A Taylor expansion for $\widetilde{\digamma}(a)$ reads $d \widetilde{\digamma}(a)=\left[\frac{\partial \digamma}{\partial a}\right]_{a^{*}} d a+$ residual. Taking norms yields that

$\|d \widetilde{\digamma}(a)\| \leqslant\left\|\left[\frac{\partial \digamma}{\partial a}\right]_{a^{*}}\right\|\|d a\|+\|$ residual $\|$

$\Rightarrow\|d \widetilde{\digamma}(a)\| \leqslant\left\|\left[\frac{\partial \digamma}{\partial a}\right]_{a^{*}}\right\|\|d a\|$

and since FTPL regimes imply that $\frac{\partial \widetilde{\digamma}}{\partial a}<1$ we obtain that $\|d \widetilde{\digamma}(a)\| \leqslant\|d a\|$. QED.

We are now at the point where we can use our model to obtain a generalization of the results in Sims (1994) to environments that feature distortionary financing and capital accumulation:

Proposition 7 Any isolated equilibrium brought about by an active regime with three explicit targets displays global determinacy.

Proof By construction, the economy is in equilibrium if and only if $\forall t \in[0,+\infty) a_{t}=\widetilde{\digamma}\left(a_{t}\right)$, where the function $\widetilde{F}\left(a_{t}\right)$ returns the present value of future primary surpluses given the state of the economy. In particular, equilibrium is globally determinate if we can pin down the initial values of financial wealth and nominal prices. Formally, the equilibrium displays global determinacy if we can obtain an $a_{0}$ that is a solution to 
$a_{0}=\widetilde{\digamma}\left(a_{0}\right)$. According to Mann's and Bailey's theorems, if $\widetilde{\digamma}$ has a fixed point, then we can construct a sequence that converges to the fixed point for all choices of initial guesses in its domain. As we know, in the steady state $a^{*}=\widetilde{\digamma}\left(a^{*}\right)=$ $\frac{1}{\rho}\left[f\left(k^{*}\right)\left(\tau^{*}+\frac{1}{\nu} R^{*}\right)-T^{*}\right]$. Now let a shock hit the economy, then we should obtain an initial valuation of government debt that is consistent with equilibrium in some interval around $a^{*}$. Note that there is an interval around the steady state, not necessarily small, where $\widetilde{\digamma}$ takes $\left[a^{*}-\varepsilon_{a}, a^{*}+\varepsilon_{a}\right]$ into itself, and from proposition 6 we know that under active fiscal rules $\widetilde{\digamma}$ is non-expanding. Thus, we can apply the Krasnoselski-MannBailey Theorem to obtain a solution to the fixed-point problem $a_{0}=\widetilde{\digamma}\left(a_{0}\right)$ as follows:

a) Choose $a_{0,1}=a^{*}$ as the initial guess, and

b) calculate a sequence by defining $a_{0, n+1}=\frac{1}{2}\left[a_{0, n}+\widetilde{\digamma}\left(a_{0, n}\right)\right]$.

c) As $n$ goes to infinity the sequence $a_{0, n}$ converges to $a_{0}$, and $\widetilde{\digamma}\left(a_{0}\right)=a_{0}$ is the initial valuation of government liabilities after the shock that is consistent with an equilibrium which displays global determinacy. QED.

We were thus able to show that given a shock and $k_{0}>0$, a regime that corresponds to FTPL and induces an isolated equilibrium also induces a unique initial valuation $a_{0}$ of noncapital wealth, and as a result a unique $P_{0}=\frac{M_{0}+B_{0}}{a_{0}}$, hence displaying global determinacy. The mechanism that brings about a unique valuation of debt so as to satisfy $a_{0}=\widetilde{\digamma}\left(a_{0}\right)$ is in operation only under FTPL regimes. By contrast, debt revaluation is not in operation under regimes that feature passive fiscal policies, i.e. that exhibit $\gamma \geqslant \rho \widetilde{a}^{*}$. In such regimes, innovations in the real value of government debt are met by actions that initially fully offset the increase in government debt by causing a one-for-one increase in the present value of future surpluses.

\section{Local-Determinacy Bounds in the Policy Parameter Space}

In this section we discuss the local stability properties of our model. We show that relative to the results found in Leeper (1991), a new regime exists. In the new regime, a passive 
fiscal rule combined with a passive monetary rule can still deliver a locally unique bounded rational expectations equilibrium where the same area of the parameter space would lead to multiple solutions if taxes were lump-sum.

\subsection{Necessary Conditions for Determinacy - An Analytical Ap- proach}

A simple example delivers the main intuition of the analysis. Consider fiscal rules that exhibit $\phi_{\gamma}>1$ [i.e., fiscal policy is passive]. Note that we know by now that all fiscal rules must

exhibit $\phi_{\beta}>0$, and that the condition $\phi_{\alpha}\left[\phi_{\beta}+\phi_{\gamma}\left(\mathcal{R S} \mathcal{F}^{*}-1\right) \frac{\tau^{*}}{1-\varphi^{*}}\right]<0$ must always hold [see Proposition 4]. Now assume an economy where the rate of self-financing is equal to or greater than one. In this case, Proposition 4 indicates that monetary policy must exhibit $\phi_{\alpha}<0$, meaning that it must be passive. Consider now economies where the rate of selffinancing of tax cuts is less than one. In such economies, a passive monetary policy must interact with fiscal policies that reside in a range $\phi_{\gamma} \in\left[0, \overline{\phi_{\gamma}}\right)$, where $\overline{\phi_{\gamma}}=\frac{\phi_{\beta}}{\left(1-\mathcal{R S F}^{*}\right) \frac{\tau^{*}}{1-\varphi^{*}}}$. Note that the measure of the interval $\left[1, \overline{\phi_{\gamma}}\right)$, where fiscal policy is passive, increases as the rate of self-financing approaches one. Formally, in the limit, $\overline{\phi_{\gamma}} \underset{\mathcal{R S F}^{*} \uparrow 1}{\rightarrow}+\infty$, which indicates that the range of passive fiscal policies that must interact with passive monetary rules grows to infinity as the rate of self-financing approaches one from below.

A few issues deserve attention at this point. First, it is implicitly argued throughout that the change in results relative to Leeper (1991) stems from distortionary taxation, and that the liquidity-in-advance specification alone does not deliver these changes. It is important to show that the features of the model which produce the different determinacy regimes come from the tax distortions and not from the liquidity-in-advance assumption. Furthermore, we need to verify that our continuous-time framework is well behaved in the sense of Carlstrom and Fuerst (2005). These ideas are formalized in Lemma 1:

Lemma 1 In our model economy, if a) the government receives access to lump-sum taxation, and b) the distortionary income-tax rate is set to zero, then:

a) The passive-fiscal-passive-monetary regime does not exist; and

b) determinacy bounds are identical to those obtained in Leeper (1991); and 
c) the model correctly approximates the behavior of the discrete time model of Carlstrom and Fuerst (2005) with arbitrarily small periods.

Finally, we assert that distortionary taxation brings about a range $\left[1, \overline{\phi_{\gamma}}\right)$ of passive fiscal policies that must interact with passive monetary policies. We thus need to show that the measure of this range is non-negligible:

Proposition 8 If fiscal policy acts according to eq. (14) and the policy targets induce $R S F^{*}<1$, then there exists a non-negligible range $\left[1, \overline{\phi_{\gamma}}\right)$ of passive fiscal policies where equilibrium is determinate only if monetary policy is passive.

\subsection{Sufficient Conditions for Determinacy - An Analytical Ap- proach}

Due to the complexity of local stability analysis of $4 \mathrm{x} 4$ systems, in what follows we focus on a baseline regime for which it is possible to obtain sufficient conditions for real determinacy. We then perturb the baseline regime so as to approximate the general case. Consider a fiscal rule that exhibits $\phi_{\gamma}=0$. Under this stance, the system (29) becomes

$$
\dot{x_{t}}=B_{[\gamma=0]} \times\left(x_{t}-x^{*}\right)
$$

where

$$
B_{[\gamma=0]}=\left[\begin{array}{ll}
\widehat{B_{1}} & \varnothing \\
\widehat{B_{2}} & \rho
\end{array}\right]
$$

and where $\widehat{B_{1}}$ is the upper left $3 \times 3$ submatrix of $B, \widehat{B_{2}}$ is the $1 \times 3$ vector $\left(B_{4,1}, B_{4,2}, B_{4,3}\right)$, and $\varnothing$ is a $3 \times 1$ vector of zeros. Examining $B_{[\gamma=0]}$, the dynamics of $(c, \pi, k)$ are independent of government liabilities. This feature has two implications: a) one eigenvalue of the $(c, \pi, k, a)$ system is $\rho>0$; b) the remaining three eigenvalues are determined by $\widehat{B_{1}}$ so that the dynamics of $(c, \pi, k)$ are completely determined by $\widehat{B_{1}}$. It is straightforward to show that the three remaining eigenvalues satisfy 


$$
\begin{aligned}
r_{1} r_{2} r_{3} & =-\kappa \phi_{\alpha} \phi_{\beta} \\
r_{1}+r_{2}+r_{3} & =\rho+\left(\nu+R^{*}\right) \phi_{\alpha}+f_{k}^{*},
\end{aligned}
$$

which leads us to the following proposition:

Proposition 9 Assuming $\phi_{\gamma}=0$, a unique rational expectations equilibrium exists only if monetary policy exhibits $\phi_{\alpha}<0$. A sufficient condition for determinacy is that $\phi_{\alpha}<-\frac{\rho+f_{k}^{*}}{\nu+R^{*}}<0$.

Proposition 10 Consider a regime $\left(\phi_{\bar{\alpha}}, \phi_{\bar{\beta}}, 0\right)$ that induces real determinacy near a hyperbolic steady state $x^{*}$. Then, perturbations to $\gamma$ in the neighborhood of $\bar{\gamma}=0$ do not change the phase portrait of $x^{*}$ as long as $\gamma$ is not perturbed until its bifurcation point. Specifically, given $\phi_{\bar{\alpha}}<0$ and $\phi_{\bar{\beta}}>0$, any regime that exhibits $\phi_{\gamma}>0$ will also induce a locally determinate equilibrium as long as the multiple of eigenvalues in the perturbed system does not change signs.

Proposition 9 argues that near a hyperbolic steady state $x^{*}$ where fiscal policy targets only output, a passive monetary rule induces a determinate equilibrium path. Proposition 10 argues that some perturbations to the fiscal rule near $x^{*}$ can preserve determinacy even if they cause the fiscal rule to exhibit a passive stance. This result obtains whenever policy perturbations near $x^{*}$ comply with the following principles: a) monetary policy remains passive; b) according to Proposition 4, tax-rate responses to output must exhibit $\phi_{\beta}>0$; and c) any deviation from the baseline regime must satisfy inequality (34). Note that it is straightforward to derive from our model that

I) $\frac{d \ln \left[\frac{1-\tau\left(k_{t}, a_{t}\right)}{1+\frac{1}{\nu} R\left(\pi_{t}\right)} f^{\prime}\left(k_{t}\right)\right]}{d \ln a_{t}} \approx-\frac{\rho \widetilde{a}^{*}}{1-\tau^{*}} \phi_{\gamma}$,

II) $\frac{d \ln \left[\frac{1-\tau\left(k_{t}, a_{t}\right)}{1+\frac{1}{\nu} R\left(\pi_{t}\right)} f^{\prime}\left(k_{t}\right)\right]}{d \ln f\left(k_{t}\right)} \approx-\frac{1}{1-\tau^{*}} \phi_{\beta}$, and since monetary policy is passive in the baseline regime, inequality (34) implies that perturbations to the fiscal rule near $x^{*}$ preserve determinacy if they exhibit

III) $\phi_{\beta}+\phi_{\gamma}\left(\mathcal{R} \mathcal{S} \mathcal{F}^{*}-1\right) \frac{\tau^{*}}{1-\varphi^{*}}>0$. 
Substituting (I) and (II) into (III) yields that perturbations to the fiscal rule around $x^{*}$ preserve the phase portrait, and hence equilibrium determinacy, as long as the interaction between fiscal policy and monetary policy induces

$$
\rho \widetilde{a}^{*} \frac{d \ln a_{t}}{d \ln y_{t}}>\left(1-\mathcal{R S F}^{*}\right) \frac{\tau^{*}}{1-\varphi^{*}} .
$$

This result is crucial to understanding why a new regime emerges under distortionary taxation and is absent where taxation is lump-sum. The left-hand side shows the rate of growth of debt/GDP when the economy is not in the steady state. The right-hand side is the slope of the government's revenue schedule, taking into account the general equilibrium effect of tax increases on all sources of revenue [i.e., tax collections and seigniorage]. The upshot of Proposition 10 is that whenever debt/GDP grows faster than the government's ability to raise revenues via tax increases, there is no point in trying to stabilize inflation expectations. Where the government has access only to distortionary taxation, tax revenues become a feature of equilibrium. In this case, output, inflation, and the tax rate are determined simultaneously in equilibrium, and the government cannot fully control its revenues. In such an environment, distorting taxes imply that there is a natural limit to revenue growth. As a result, the government may encounter situations where it is unable to finance its commitments entirely through direct tax collections. If spending commitments cannot be financed entirely through direct taxes, policies must be adjusted so as to be consistent with a rational expectations equilibrium. One way to do this is to renege on some of the government's promised transfers. Alternatively, the government can choose either to devalue its debts this is achieved under the FTPL regime - or to fulfill its obligations by providing any required backstops. The second choice, which has a bearing on Sims's (1994) notion of fiscal backstops, is achieved in our model under the UMA regime. Table 1 summarizes the key differences between the various regimes. 
Table 1 - Regimes under distortionary taxation

\begin{tabular}{|c|l|c|c|c|}
\hline Regime & \multicolumn{1}{|c|}{ Feasibility } & Monetary policy & Fiscal policy & Nominal prices \\
\hline \hline Taylor-rules & $\rho \widetilde{a}^{*} \frac{d \ln a_{t}}{d \ln y_{t}}<\left(1-\mathcal{R S F}^{*}\right) \frac{\tau^{*}}{1-\varphi^{*}}$ & $\phi_{\alpha}>0$ & $\phi_{\gamma}>1$ & QT \\
\hline FTPL & $\rho \widetilde{a}^{*} \frac{d \ln a_{t}}{d \ln y_{t}}>\left(1-\mathcal{R S F}^{*}\right) \frac{\tau^{*}}{1-\varphi^{*}}$ & $\phi_{\alpha}<0$ & $\phi_{\gamma}<1$ & FTPL \\
\hline UMA & $\rho \widetilde{a}^{* \frac{d \ln a_{t}}{d \ln y_{t}}}>\left(1-\mathcal{R} \mathcal{S F}^{*}\right) \frac{\tau^{*}}{1-\varphi^{*}}$ & $\phi_{\alpha}<0$ & $\phi_{\gamma}>1$ & QT \\
\hline
\end{tabular}

"QT": Nominal prices are determined according to the quantity theory of money.

"FTPL": Nominal prices are determined according to the fiscal theory of the price level.

In the FTPL regime, the fiscal authority is committed to stabilizing the income tax. In the terminology of the fiscal rule (14), the income-tax rate responds only weakly to changes in government debt (specifically, $\gamma$ is less than $\rho \widetilde{a}^{*}$ ). That means that under an FTPL regime, fiscal expansion is financed via debt increases. Fiscal expansion is supported by an appropriate monetary policy which increases current demand for goods and drives up price levels. However, letting government liabilities take an explosive path is inconsistent with equilibrium. As the fiscal authority is committed to stabilizing the tax rate, and as the tax rate has to remain bounded, equilibrium cannot be restored solely via increases to tax revenues. As a result, a debt revaluation comes to play. Note that inequality (39) obtains when an economy resides in an FTPL regime regardless of whether the government is able to increase its revenues via tax hikes. An important characteristic of FTPL regimes is that they arrive from a policy choice, and that they are feasible even when income-tax rates are low! In such a regime, a commitment to stabilize the tax rate may cause a breakdown of Ricardian equivalence, so government debt must be devalued to restore equilibrium. We can say that equilibrium is restored once the simultaneous adjustment of debt value and the expected equilibrium path of the endogenous variables bring about equality between the present value of future expected surpluses and the real value of current debt. Proposition 3 summarizes this mechanism.

In contrast, in the UMA regime the fiscal authority is committed to stabilizing public debt. This mechanism is best understood via Proposition 2: fiscal policy is designed so as to allow the fiscal authority to fund debt increases via tax collections, and as result debt devaluation is not in operation. However, if taxes are already high, or if the debt level is too high, the government's ability to finance its commitments through taxes is limited. Thus, the inflation tax required to balance the budget increases. Since monetary contractions reduce seigniorage 
revenues, aggressive responses to inflation will only increase fiscal stress and the requirement to further increase inflation. As Sims (1994) points out, this unpleasant monetary arithmetic can lead to situations in which an extremely contractionary monetary policy brings about extremely inflationary sunspot equilibria.

To rule out off-equilibrium dynamics when the economy hits its fiscal limits, uniqueness can be restored by a combination of monetary and fiscal policies that reside in the UMA regime. First, the fiscal and monetary authorities should commit to policies that satisfy the transversality condition near a specified steady state. This steady state should be identified via an inflation target, a tax-rate target and a debt/GDP target. In order to make this commitment credible, government spending in the steady state must be consistent with the proclaimed targets. ${ }^{11}$ This statement is formally given by Proposition 5. The next step is to rule out the inflationary sunspot equilibria. This can be done by means of a simple policy, whereby the monetary authority can announce that it will back up the value of government debt, and the fiscal authority can announce that it will back up the value of the currency. The former is a credible announcement because the monetary authority can purchase from the private sector as much debt as needed at a promised price in exchange for currency. Since the main instrument of the central bank in our model is the nominal interest, such a policy simply brings about the desired nominal interest. At the same time, the fiscal authority can back up the value of the currency by exchanging money for goods, limiting the price level at some bound. This is a credible announcement because the fiscal authority can obtain the necessary goods by imposing taxes.

To conclude, there are two main characteristics that distinguish UMA regimes from FTPL regimes. First, UMA regimes are not feasible when the income tax is low. In such cases, the fiscal authority can simply increase taxes to stop its debts from growing. Second, as debt devaluation is not in operation under the UMA regime, the level of nominal prices is not linked to the debt level. As a result, the level of nominal prices is set according to the conventional concept of equality between real-money demand and supply [eq. (16)].

\footnotetext{
${ }^{11}$ In our model this is the lump-sum transfer.
} 


\section{Quantitative Analysis}

In this section we perform two quantitative exercises. The first establishes numerically the boundary conditions in the policy parameter space. The other shows impulse response functions under the three regimes that emerge in our model, when shocks perturb the economy from the steady state. To demonstrate the effect of distortionary government financing, we calibrate the model to the structural parameters of the US economy. Overviews of the structural parameters and the policy parameters are provided in Tables 2 and 3 :

\begin{tabular}{lcl}
\multicolumn{2}{c}{ Table 2 - Parameters } & \\
\hline$\rho$ & 0.04 & Subjective discount rate \\
$\sigma$ & 0.5 & Elasticity of intertemporal substitution \\
$\nu$ & 2 & M2 money velocity \\
$\delta$ & 0.1 & Capital depreciation rate \\
$1-\epsilon$ & 0.63 & Maximal tax rate \\
$\varphi^{*}$ & 0.5 & Steady state elasticity of income-tax revenues \\
$A^{*}$ & 1 & Steady state TFP \\
$\tilde{a}^{*}$ & 0.6 & Steady state Debt/GDP \\
$\pi^{*}$ & 0.02 & Steady state inflation \\
$\tau^{*}-\widetilde{T}^{*}$ (implied) & -0.006 & Steady state primary surplus/GDP \\
$\beta$ & 1 & Output gap coefficient of the fiscal rule under all regimes \\
$\rho_{R}$ & 0.35 & Persistence of monetary shocks (annual) \\
$\rho_{T}$ & 0.65 & Persistence of fiscal shocks (annual) \\
$\rho_{A}$ & 0.92 & Persistence of technology shocks (annual) \\
\hline
\end{tabular}

\section{Table 3 - Policy Parameters}

\begin{tabular}{ccccc}
\hline & & FTPL & UMA & Taylor \\
$\alpha$ & Inflation coefficient of the monetary rule & 0.5 & 0.5 & 1.5 \\
$\gamma$ & Debt coefficient of the fiscal rule & 0 & 0.034 & 0.4 \\
\hline
\end{tabular}

The annual (subjective) rate of time preference and the elasticity of intertemporal substitution are set according to the general consensus. The elasticity of production technology is set so as to induce a steady-state Laffer curve that peaks at the levels obtained by Trabandt and Uhlig (2011). Specifically, $\epsilon$ is set so as to induce maximal capital tax rates of 0.63 for the US. Building on Trabandt and Uhlig (2011), tax rates are set so as to bring about

\footnotetext{
${ }^{12}$ See estimates in Leeper et. al. (2010).

${ }^{13}$ In Benhabib and Wang (2013) the auto correlations of TFP and government spending are set to 0.98 and 0.9 , respectively, in a quarterly time frequency. We use in our model the corresponding annual rates.
} 
elasticity of tax revenues of 0.5 . Money velocity corresponds to the average level of US M2 money velocity prior to the 2008 financial crisis. ${ }^{14}$ In order to show impulse response functions when shocks perturb the economy from the steady state, we add to the model monetary shocks, fiscal shocks, and technology shocks. We model monetary innovations as persistent shocks to the nominal rate of interest. We model fiscal innovations as persistent shocks to promised transfers. Finally, we model technology as persistent shocks to TFP. Accordingly, we augment the system (18)-(21) to include AR(1) processes for TFP, real lump-sum transfers, and nominal interest. This addition to the model does not change the model's determinacy properties [see proof in the technical appendix].

\section{Figure 1 enters here}

Previous literature defines "active" and "passive" authorities based on policy parameters needed to give determinacy based on eigenvalues. We adhere to this terminology to discuss the local stability properties of the equilibrium. Figure 1.1 shows the phase portrait of the US economy where the income-tax rate is set to zero and the rate of self-financing is one. ${ }^{15}$ When we set the income-tax rate to zero, the determinacy bounds coincide with those of Leeper (1991) and its subsequent literature. In this case, two demarcation lines, a horizontal line at $\alpha=1$ and a vertical line at $\gamma=\rho \widetilde{a}^{*}$, divide the parameter space into four areas that correspond to four regimes, reestablishing Leeper's (1991) well-known result. In the absence of tax distortions, two regimes bring about local determinacy. The first regime, corresponding to the Taylor rules, is where active monetary rules interact with passive fiscal rules. The second regime, corresponding to FTPL, is where passive monetary rules interact with active fiscal rules. Distortionary financing changes the conditions for fiscal policy, and they are given by the terms in brackets in Proposition 4. These conditions, based on eigenvalues, split the determinacy regions in the $(\gamma, \alpha)$ space into two distinct spaces, as shown by Figure 1.2. In addition, the demarcation line that indicates a violation of the government's budget constraint - according to Proposition 3, the demarcation line is at $\gamma=\rho \widetilde{a}^{*}-$ further splits

\footnotetext{
${ }^{14}$ Source: Federal Reserve Bank of St. Louis - Velocity of M2 Money Stock, Ratio, Quarterly, Seasonally Adjusted.

${ }^{15}$ In these cases the lump-sum transfer, $\widetilde{T}^{*}$, is adjusting to changes in debt, $\tilde{a}^{*}$, as in Leeper (1991).
} 
the fiscal conditions from this expression when monetary policy is passive into two different regimes. Figure 1.2 shows that distortionary taxation brings about determinacy bounds that differ from the conventional result. In these figures a UMA regime emerges, where a passive fiscal policy interacts with a passive monetary policy [see the light-grey area to the right of the demarcation line $\gamma=\rho \widetilde{a}^{*}$ in Figure 1.2]. This area takes a non-negligible size in the parameter space.

Let us now use our calibrated model to study the impulse responses of our model, where we explore the implications of regime choices on aggregate dynamics. All graphs present the percentage deviations of the model variables from their steady-state levels.

\section{Figure 2 enters here}

\section{Figure 3 enters here}

Figure 2 displays the responses to an expansionary monetary shock, where the central bank initially reduces the nominal rate of interest by $1 \%$. In the UMA and Taylor regimes the initial value of government debt is taken as given. Thus, the impulse response shows initially that government debt remains at its level prior to the shock. The central bank then purchases government bonds in the open market so as to bring about the desired reduction to nominal interest. This drains the amount of government debt held by households, and real debt falls below its long-run level. Thus, the continuous decline in debt levels that we observe under the UMA and Taylor regimes shortly after the monetary innovation is caused mainly by monetary policy. Note, however, that in equilibrium the real value of debt must equal the present value of future surpluses. Since UMA and Taylor regimes imply, to some extent, responsiveness of the income tax to debt levels, tax rates indeed fall in response to lower debt. This mechanism is in operation under the UMA and Taylor regimes. By contrast, under the FTPL regime tax rates are not expected to respond to government debt. Thus, if tax revenues are expected to increase, perhaps because of GDP growth, then the present value of future surpluses rises. We observe this upshot as an increase in the real value of government debt under the FTPL regime. 
Figure 3 displays the responses to a fiscal shock that initially increases real lump-sum transfers by $5 \%$. Where the fiscal shock is persistent, the buildup in government debt should be gradual. Figure 3 reemphasizes the channels through which the monetary-fiscal policy interaction operates under the three regimes. In the UMA and Taylor regimes the initial value of government debt is taken as given. Thus, the impulse response shows initially that government debt remains at its level prior to the shock. Under a Taylor rule, fiscal policy is passive, which means that tax rates respond aggressively to an increase in government debt so as to increase tax revenues. Such a response sends the economy into a downturn. By contrast, under the UMA regime tax rates respond weakly to government debt. However, Figure 3 shows that under UMA, the real value of government debt falls even though fiscal policy is expansionary and inflation is nearly unchanged. Also note that in this regime the nominal interest is nearly pegged. This is exactly what the monetary backstop does. The time path of debt stems mainly from purchases of government debt in the open market by the central bank so as to induce the desired rate of nominal interest. All in all, a UMA regime reduces the distorted marginal product of capital and, as a result, consumption increases due to a substitution effect. Finally, under the FTPL regime, tax rates are expected to respond very little to government debt, whereas transfers increase. As a result, the present value of future surpluses falls, and so to restore equilibrium debt must be devalued.

\section{Concluding Remarks}

This paper formalizes the consequences of combining changes in the level of income tax and the nominal rate of interest so as to achieve long-run levels of public debt, inflation, and output. It augments the Ramsey-Cass-Koopmans model to include distortionary taxation and a liquidity constraint. The paper constructs a dynamic environment that circumvents complications associated with dynamic Laffer curves. In this environment, tax cuts are selffinancing at rates higher than one minus the slope of the income-tax Laffer curve, because general equilibrium effects of tax cuts increase seigniorage revenues. The paper then ana-

lytically characterizes constraints on fiscal and monetary policy for determinacy, and shows that relative to previous literature, a new area of determinacy exists where fiscal policy and 
monetary policy are both passive. In this regime, prices are determined according to the quantity theory of money. As a result, and since a unique rational expectations equilibrium exists, weak responses of the nominal interest rate to expected inflation are consistent with inflation increasing when government debt seems to take an explosive path. This mechanism stands in sharp contrast to the mechanisms that restore equilibrium either under the conventional Taylor-rule regime or under regimes that emphasize debt revaluation. Comparing impulse responses of the model economy across the different regimes shows that UMA is a truly distinct regime.

Two issues deserve attention. First, only two policy parameters determine the regime in which the economy resides: the monetary response to inflation, and the tax-rate response to government debt. The response of the tax rate to output plays no role in the determinacy results to the extent that such responses are "reasonable". In the context of our model, "unreasonable" responses to output include extremely procyclical fiscal policies. Second, assuming lump-sum taxation together with financial friction delivers only two determinacy bounds that correspond to the determinacy bounds obtained in Leeper (1991). This means that financial frictions imposed on real investment play no role in bringing about a UMA regime. Nevertheless, this constraint on investment is required so as to induce an intertemporal no-arbitrage condition between bonds and capital at the household level, which lets

our continuous-time framework correctly approximate the behavior of a discrete-time model with arbitrarily short periods. In addition, it creates an important role for monetary policy in economies where the government has access only to distortionary taxation. Where investment decisions are distorted by both income taxes and interest rates, monetary policy can alleviate the effect of tax hikes by reducing the nominal rate of interest. These features are important for the quantitative relevance of our model.

\section{Acknowledgments}

I thank Marco Bassetto, Matthias Doepke, Josè-Victor Rios-Rull, participants at the 2014 Asian Meeting of the Econometric Society, EEA 2015, and seminars at the Bank of Israel, Haifa University, and Tel-Aviv University for comments on earlier versions of this paper. Special thanks go to Thomas Lubik (the editor) and two anonymous referees for excellent 
suggestions.

\section{References}

[1] Abel, A. B. ,1985, Dynamic Behavior of Capital Accumulation in a Cash-in-Advance Model, Journal of Monetary Economics, 16, 55-71.

[2] Alvarez F., R. E. Lucas Jr., and W. E. Weber, 2001, Interest Rates and Inflation, The American Economic Review, 91, 219-225.

[3] Bailey, D. F., 1974, Krasnoselski's Theorem on the Real Line, American Math. Monthly, 81, 506-507.

[4] Benhabib, J., and S. Eusepi (2005), The design of monetary and fiscal policy: a global perspective, Journal of Economic Theory 123, 40-73.

[5] Benhabib, J. and P. Wang, 2013, Financial Constraints, Endogenous Markups, and Self-fulfilling Equilibria, Journal of Monetary Economics, 60, 789-805.

[6] Bhattarai, S. , J. W. Lee, and W. Y. Park, 2012, Inflation Dynamics: The Role of Public Debt and Policy Regimes, Journal of Monetary Economics,forthcoming.

[7] Bi, H., 2012, Sovereign Default Risk Premia, Fiscal Limits, and Fiscal Policy, European Economic Review, 56 ,389-410.

[8] Bi, H., and N. Traum, 2012, Empirical Approaches to Sovereign Debt Default and Monetary-Fiscal Interactions, American Economic Review: Papers \& Proceedings, 102, $161-166$.

[9] Bi, H., E. M. Leeper and C. B. Leith, 2013, Uncertain Fiscal Consolidations, The Economic Journal, 123, F31-F63.

[10] Buiter, W. H., 1984, Saddlepoint Problems in Continuous Time Rational Expectations Models: A General Method and some Macroeconomic Examples, Econometrica, 52, 665-680.

[11] Carlstrom, C.T., and T.S. Fuerst (2005), Investment and interest rate policy: a discrete time analysis, Journal of Economic Theory 123, 4-20.

[12] Cochrane, J. H., 2011, Determinacy and Identification with Taylor Rules, Journal of Political Economy, 119, 565-615.

[13] Cochrane, J. H., 2014, Monetary policy with interest on reserves, Journal of Economic Dynamics and Control, 49, 74-108. 
[14] Guckenhaimer, J., and Holmes, P. ,1983, Nonlinear Oscillations, Dynamical Systems, and Bifurcations of Vector Fields, Springer-Verlag.

[15] Hirsch, M. W., and Smale S. ,1976, Differential Equations, Dynamical Systems, and Linear Algebra, Academic Press.

[16] Hodrick, R. J., Kocherlakota N., and Lucas D., 1991, The Variability of Velocity in Cash-in-Advance Models, Journal of Political Economy, 99, 358-384.

[17] Krasnoselski, M. A., 1955, Two Remarks on the Method of Successive Approximations, Uspehi Math. Nauk, (1) 10, 123-127.

[18] Leeper, E. M., 1991, Equilibria under 'Active' and 'Passive' Monetary and Fiscal Policies, Journal of Monetary Economics,27, 129-47.

[19] Leeper, E. M. and J. M. Nason, 2008, Government Budget Constraint, in Blume, Lawrence and Steven N. Durlauf eds. The New Palgrave Dictionary of Economics 2nd Edition, Hampshire England: Palgrave Macmillan Ltd.

[20] Leeper, E. M. and S. C. S. Yang, 2008, Dynamic Scoring: Alternative Financing Schemes, Journal of Public Economics, 92(1-2), 159-182.

[21] Leeper, E. M., M. Plante, and N. Traum, 2010, Dynamics of Fiscal Financing in the United States, Journal of Econometrics, 156(2), 304-321.

[22] Mann, W. R., 1953, Mean Value Methods in Iteration, Proc. Amer. Math., 3, 506-510.

[23] Mulligan, C. B. and X. Sala-i-Martin, 1991, A Note on the Time-Elimination Method For Solving Recursive Dynamic Economic Models," NBER Technical Working Papers 0116, National Bureau of Economic Research, Inc.

[24] Mulligan, C. B. and X. Sala-i-Martin, 1993, Transitional Dynamics in Two-Sector Models of Endogenous Growth, The Quarterly Journal of Economics, 108(3), 739-73.

[25] Sargent, T. J., and Wallace, N., 1981, Some unpleasant monetarist arithmetic, Federal Reserve Bank of Minneapolis Quarterly Review, 5, 1-17.

[26] Shimer, R. ,2012, Wage rigidities and jobless recoveries, Journal of Monetary Economics, 59, S65-S77.

[27] Sims, C. A., 1994, A Simple Model for Study of the Determination of the Price Level and the Interaction of Monetary and Fiscal Policy, Economic Theory, 4(3), 381-99.

[28] Sims, C. A., 2002, Solving Linear Rational Expectations Models, Computational Economics, 20;1-20

[29] Sims, C. A., 2013, Paper Money, The American Economic Review, 103, 563-584.

[30] Stockman, A. C. ,1981, Anticipated Inflation and the Capital Stock in a Cash-inAdvance Economy, Journal of Monetary Economics , 8(3), 387-393. 
[31] Traum, N. and S. C. S. Yang, 2011, Monetary and Fiscal Policy interactions in the Post-War U.S., European Economic Review, 55, 140-164.

[32] Trabandt, M., and H. Uhlig, 2011, The Laffer Curve Revisited, Journal of Monetary Economics, 58, 305-327. 